\title{
Culpa in vigilando. \\ El caso "Estado de México"
}

\section{Luis Espíndola Morales*}

\section{Sumario:}

I. Breve referencia

II. Evolución de la culpa in vigilando en los criterios del Tribunal Electoral

III. Aspectos relacionados con la teoría del levantamiento del velo, el abuso del derecho y el fraude a la ley

IV. Las candidaturas comunes

V. El caso "Estado de México"

VI. El voto particular

VII. Algunas reflexiones

VIII. Bibliografía

* Secretario de estudio y cuenta de la Sala Regional Toluca del Tribunal Electoral del Poder Judicial de la Federación.

D. R. (c) 2012. Universidad Nacional Autónoma de México-Instituto de Investigaciones Jurídicas. Revista Mexicana de Derecho Electoral, núm. 2, julio-diciembre de 2012, pp. 259-277, 


\section{Breve referencia}

En el ámbito del derecho administrativo sancionador, se reconoce que las personas jurídicas puedan cometer infracciones y ser sancionadas con motivo de ellas, sobre la base de un conjunto de elementos y principios tendentes a evidenciar su responsabilidad como son la culpa in vigilando, la culpa in eligendo, "el riesgo", "la buena fe", entre otros.

La culpa in vigilando o también llamada responsabilidad indirecta, en la que la doctrina destaca el deber de vigilancia que tiene la persona jurídica sobre las personas que actúan en su ámbito, ${ }^{1}$ se ha trasladado al ámbito electoral; se trata de las conductas infractoras a la normativa electoral en las que pudieran incurrir los partidos políticos al incumplir su deber de vigilancia respecto de sus candidatos, militantes, terceros o personas relacionadas con sus actividades si para evitar su comisión o continuidad de la misma deja de tomar medidas idóneas, proporcionales, objetivas y eficaces que la inhiban. ${ }^{2}$

De esta manera, en el derecho administrativo sancionador, el cual, por su naturaleza, se basa en los principios rectores de la dogmática penal, ${ }^{3}$ se incluyen a los partidos políticos que, como entes de interés público, son capaces de cometer infracciones a las disposiciones constitucionales y legales en materia electoral y ser sancionados conforme a las disposiciones y principios rectores de la materia, especialmente

1 Nieto García, Alejandro, Derecho administrativo sancionador, 4a. ed., Madrid, Tecnos, 2005, pp. 391 y ss.

2 Al respecto, véanse la Sala Superior del Tribunal Electoral del Poder Judicial de la Federación ha adoptado diversos criterios en cuanto al tratamiento de la culpa in vigilando de los partidos políticos, las que han quedado plasmadas en criterios como: la tesis relevante con la clave S3EL 034/2004, rubro: PARTIDos Políticos. Son IMPUTABLES POR LA CONDUCTA DE SUS MIEMbROS Y PERSONAS RELACIONADAS CON SUS ACTIVIDADES, visible a fojas 754 a 756 de la Compilación Oficial de Jurisprudencia y Tesis Relevantes 1997-2005, con el rubro: PARTidos Políticos. Son imputables Por LA CONDUCTA DE SUS MIEMBROS Y PERSONAS RELACIONADAS CON SUS ACTIVIDADES. Así como: ReSPONSABILIDAD DE LOS PARTIDOS POLÍTICOS POR ACTOS DE TERCEROS. CONDICIONES QUE DEBEN CUMPLIR PARA DESLINDARSE, consultable en la Gaceta de Jurisprudencia y Tesis en Materia Electoral, Órgano de difusión de los criterios emitidos por el Tribunal Electoral del Poder Judicial de la Federación, año 3, núm. 6, 2010, p. 33

3 Véase Tesis XLV/2002, con el rubro: Derecho administrativo SANCIONAdor ELECTORAL. LE SON APLICABLES LOS PRINCIPIOS DEL IUS PUNIENDI DESARROLLADOS POR EL DeReCho penal, consultable en Justicia Electoral. Revista del Tribunal Electoral del Poder Judicial de la Federación, Suplemento 6, año 2003, pp. 121 y 122. 
por conductas de sus dirigentes, simpatizantes, militantes o cualquier persona física o jurídica que se encuentre directa o indirectamente vinculada con sus actividades, en especial, cuando se trata de origen, uso y destino del financiamiento.

Una situación similar sucede cuando los partidos políticos participan coaligados en la contienda electoral, ya que, de esta manera, los beneficios y pérdidas que sean consecuencia de ello deben distribuirse entre los partidos que la conforman, aun cuando la coalición desaparezca una vez concluido el objeto para el que fue creada, puesto que, su disolución de ninguna forma implica la desaparición de las sanciones que, con motivo de las infracciones a la normativa y principios rectores de la función electoral pudieran derivar de su participación en alguna de las etapas del proceso electoral; aspecto que también es acorde con los principios generales del derecho que rezan beneficium datur propter officium (el beneficio se confiere en razón de la obligación) y eius sit onus cuius est emolumentum (quien aprovechó los beneficios esté a las pérdidas). ${ }^{4}$

Otra forma de participación es a través de las candidaturas comunes, figura jurídica que, en esencia, consiste en la postulación de candidatos a cargos de elección popular por dos o más partidos políticos, quienes convienen, entre otros aspectos, el origen partidario de cada uno de los candidatos, así como la forma y términos en los cuales aportarán recursos y esfuerzos en el proceso electoral de que se trate; de esta manera se genera un vínculo o nexo jurídico para los partidos políticos que participan bajo esta modalidad respecto a los derechos y cargas que represente su intervención en el proceso electoral.

Ahora bien, de los supuestos citados, la pregunta es ¿qué ocurre con los casos de candidatura común, en que existe un nexo jurídico entre los partidos políticos que la conforman, en los que se obtiene un beneficio pero no una obligación jurídica de contar con un órgano administrativo en los casos en que uno de los partidos supera los topes de gastos de campaña y los otros no? La Sala Regional Toluca, resolvió un caso en el que se planteó esta interrogante.

En el caso de las candidaturas comunes, como se adelantó, se presenta una situación diversa, puesto que, mediante esta forma de par-

Al respecto, véase Tesis S3EL 116/2001, con el rubro: SANCión a UNA COALICIÓN POLÍticA DESINTEGRADA. DEBE SER IMPUESTA A LOS PARTIDOS POLÍTICOS QUE LA CONFORMARON, consultable en la Compilación Oficial de Jurisprudencia y Tesis Relevantes 1997-2005, p. 915. 
ticipación, los partidos políticos aportan financiamiento y esfuerzos a efecto de postular candidatos en común. Es en este aspecto donde resulta necesario establecer si existe la posibilidad de que se pueda fincar o no responsabilidad por culpa in vigilando a un partido político que aportó financiamiento a la candidatura y que por su parte no rebasó los topes de gastos de campaña establecidos por el órgano administrativo electoral, pero que, con motivo del rebase de topes de gastos de campaña por algunos de los partidos políticos que la conforman, exista la posibilidad de fincarle responsabilidad indirecta al haber incumplido un deber de vigilancia que le correspondía, la cual deriva de su participación bajo esta figura jurídica.

Antes de exponer la postura que asumió la Sala Regional Toluca en un caso similar, es pertinente exponer el panorama que circunda al tema en cuestión.

\section{Evolución de la culpa in vigilando en los criterios del Tribunal Electoral}

Existen muchos criterios en los que el Tribunal Electoral del Poder Judicial de la Federación se ha pronunciado respecto a la culpa in vigilando y sus alcances, por esto citaré sólo algunos, los cuales, por su trascendencia, han marcado directrices en la responsabilidad indirecta de los partidos políticos.

El primero de ellos, es el caso conocido como "Amigos de Fox" que derivó del expediente SUP-RAP-98/2003 y acumulados, en el que se abordó el tema de responsabilidad por rebase de topes de gastos de campaña por la coalición "Alianza por el Cambio", conformada por los partidos Verde Ecologista de México y Acción Nacional, emanada de la elección de presidente de los Estados Unidos Mexicanos, se demostró la existencia de un financiamiento paralelo en la campaña del candidato a la Presidencia de la Republica postulado por dicha coalición. En el referido fallo, la Sala Superior estableció, en esencia, que si bien el candidato de la coalición había surgido de las filas del Partido Acción Nacional, lo cierto era que el Partido Verde Ecologista de México (PVEM), al ser integrante de dicha coalición se había colocado en una posición de garante respecto a su candidato por lo que se confirmó la sanción que el Instituto Federal Electoral le impuso por responsabilidad indirecta. 
En esta sentencia también se consideró que al PVEM le era inmanente el deber de vigilancia de los actos de su candidato, especialmente aquellos que tuvieran que ver con el financiamiento dirigido a la obtención del triunfo en los comicios presidenciales, e incluso por actos de terceros, con incidencia en el aspecto de apoyo financiero para la consecución de ese fin.

En dicho fallo se expuso que el PVEM pudo haberse asegurado de que los recursos utilizados en la etapa previa a la campaña, en la propia campaña y en forma posterior, estuvieran dentro del marco legal, es decir, sólo mediante la vigilancia de los actos realizados por su candidato y de los terceros que aportaron recursos, por lo que, en todo caso, el citado instituto político pudo haber tenido la certeza de que las aportaciones no provenían de alguna de las fuentes prohibidas por la ley, tales como personas que vivan o trabajen en el extranjero, empresas mexicanas de carácter mercantil, etcétera; igualmente, de haber cumplido con esa actitud vigilante habría tenido la certeza de que el monto de tales recursos no provocaría que fueran rebasados los topes señalados en la ley respecto a las aportaciones de simpatizantes, ni los topes de campaña aprobados por el Consejo General del Instituto Federal Electoral.

De las aportaciones relevantes de la referida resolución destaca, desde luego, la relativa a que el PVEM incumplió con dicho deber de vigilancia, porque al haber estado en aptitud de conocer la existencia del referido financiamiento paralelo, no realizó ningún acto que tuviera por objeto notificar a la autoridad administrativa electoral sobre esa circunstancia. Un dato importante para fincar esta responsabilidad al PVEM, fue el relativo al comparativo que realizó la Sala Superior del Tribunal Electoral del Poder Judicial de la Federación en cuanto a los diputados que dicho instituto político obtuvo en las elecciones intermedias de 1997 con respecto a las de 2000 o bien, haber incrementado considerablemente su financiamiento público derivado de su participación en la coalición que contendió en la elección presidencial de ese año, con lo que se evidenciaba el beneficio indebido que obtuvo a través del financiamiento irregular que finalmente quedó demostrado ante el Tribunal Electoral. ${ }^{5}$

5 Véase Córdova Vianello, Lorenzo y Murayama, Ciro, Elecciones, dinero y corrupción. Pémexgate y Amigos de Fox, México, Cal y Arena, 2006, pp. 211 y 212. 
Otro asunto de especial relevancia es el recurso de apelación con la clave SUP-RAP-018/2003, caso que a la postre se conocería como "Pemexgate", derivado del escándalo que produjo la participación financiera del sindicato de Petróleos Mexicanos a favor de la campaña presidencial del candidato del Partido Revolucionario Institucional (PRI) en la elección de 2000. En dicho fallo, el Tribunal Electoral señaló entre otras cosas, que la conducta de los miembros de dicho sindicato, algunos de los cuales tenían cargos al interior del partido, pudo ser prevista por el PRI en cuanto a las aportaciones irregulares de las que se benefició y que, por tanto, ante la conducta del referido instituto político debía ser sancionado.

Este asunto destaca, por su relevancia, la adopción por el Tribunal de la tesis del levantamiento del velo, puesto que el PRI sostenía que no podía resultar responsable por los actos que cometieran personas físicas. Al respecto, el Tribunal determinó que era impensable que las personas jurídicas podían cometer ilícitos por sí mismas, dado que por su propia naturaleza carecen de un elemento volitivo propio, $y$ que, en consecuencia era natural que actuaran y eventualmente cometieran ilícitos a través de personas físicas. ${ }^{6}$

En materia de financiamiento se estableció, además, que el deber de vigilancia de los partidos políticos se extiende a todas las normas que regulan los tipos de financiamiento permitidos, los topes de gastos de campaña, la prohibición de recibir aportaciones de determinadas personas, los límites de aportaciones de los simpatizantes, la obligación de rendir cuentas, etcétera; puesto que de ellas depende el principio constitucional de la equidad que debe regir en las contiendas democráticas. ${ }^{7}$

Acorde con lo anterior, al resolver el expediente SUP-JDC-285/2008, relativo a la imposición de una sanción al partido político por culpa in vigilando, se reconoció también el interés jurídico de los simpatizantes y militantes cuya conducta la motivó. ${ }^{8}$

${ }^{6}$ Ibidem, p. 107.

7 Ibidem, p. 108.

8 Al respecto véase la tesis relevante XXIX/2008, rubro: INTERÉs JURÍDICO. MILITANTES Y SIMPATIZANTES CUYA CONDUCTA GENERÓ LA IMPOSICIÓN DE UNA SANCIÓN A LOS PARTIDOS POLÍTICOS POR CULPA IN VIGILANDO, RECONOCIMIENTO DE, consultable en la Gaceta de Jurisprudencia y Tesis en materia electoral, Tribunal Electoral del Poder Judicial de la Federación, año 2, núm. 3, 2009, pp. 43 y 44. 
Siguiendo esta tendencia, al resolver el expediente con la clave SUPRAP-186/2008, sobre los spots transmitidos por el Consejo Coordinador Empresarial en la elección presidencial de 2006, la Sala Superior determinó que debía sancionarse a los partidos políticos Revolucionario Institucional, Verde Ecologista de México y Acción Nacional, al considerar la existencia de un "nexo" por beneficiarse con su transmisión, puesto que los mismos estaban encaminados a difundir propaganda negativa contra la coalición "Por el Bien de Todos" por lo que, si bien dichos partidos políticos habían manifestado su repudio por dichos spots, lo cierto era que no existía constancia de que hubieran implementado algún medio eficaz a efecto de evitar la continuidad de las faltas, de las cuales se habían beneficiando, colocándolos en su calidad de garantes respecto de dichas conductas.

En el expediente SUP-RAP-201/2009, se determinó la responsabilidad por culpa in vigilando del PVEM cuyo tema central fue la transmisión de spots de una revista en la que se hacía alusión a las propuestas de campaña del instituto político de referencia. En este sentido, en la sentencia se expuso que si bien el PVEM había contratado únicamente la difusión en medio impreso de la revista, lo cierto era que con motivo del contrato celebrado entre éste y la empresa publicitaria, existía un vínculo indisoluble de los contratantes del que deriva un deber de vigilancia entre las partes que intervinieron en el contrato, cuyo incumplimiento se traducía en responsabilidad indirecta por la inobservancia de la conducta infractora desplegada por el co-contratante.

En dicho precedente la Sala Superior determinó que, en estos casos, los contratantes deben sujetarse, entre otros aspectos a: 1) las obligaciones pactadas; 2) vigilar que el cumplimiento del contrato no caiga en la ilicitud del objeto o fin, y 3) garantizar que el prestador del servicio no exceda en el cumplimiento del contrato o lleve a cabo actos que vulneren normas de orden público; aspectos que implicaban que el partido político garantizara que su propaganda política pagada para aparecer únicamente en la revista de espectáculos, no fuera transmitida en televisión, ya que, si bien no contaba con la calidad de garante frente a la televisora que trasmitió los spots, lo cierto era que debía realizar actos encaminados a su retiro, por lo que ante su pasividad para actuar diligentemente condujo a sostener el incumplimiento de su calidad de garante, lo que denotaba su falta de cuidado, previsión, control, y supervisión, incurriendo por tal motivo en responsabilidad. 
En cuanto a la existencia de responsabilidad bajo la figura de culpa in vigilando no se requiere prueba de responsabilidad directa, ni acreditación fehaciente del conocimiento del acto irregular, sino que basta con demostrar que objetivamente el partido político estuvo en aptitud de conocerlo y que éste le hubiera beneficiado.

La culpa in vigilando constituye una forma de responsabilidad indirecta en la que el partido político no interviene por sí o a través de otros, en la comisión de la infracción, sino que incumple con un deber de vigilancia por no efectuar los actos necesarios para prevenirla o, consumada ésta, desvincularse de la misma, de modo que cuando existen pruebas de responsabilidad directa, se está bajo alguna forma de autoría o coautoría en la responsabilidad de la infracción, pero no en culpa in vigilando.

De dicho precedente se pueden tomar también como referencia las sentencias recaídas a los recursos de apelación con las claves SUPRAP/198/2011 y SUP-RAP-220/2011, en los que para efecto de establecer si en culpa in vigilando existía la posibilidad de fincar responsabilidad a los partidos políticos por conductas de terceros vinculados con sus actividades, era necesario que el partido político cuestionado adoptara medidas con base en las condiciones siguientes: $a$ ) eficacia, que consiste en que la implementación de la medida produzca el cese de la conducta infractora o genere la posibilidad cierta de que la autoridad competente conozca el hecho para investigar y resolver sobre la licitud o ilicitud de la conducta denunciada; $b$ ) la idoneidad, es decir, que la medida que implemente el partido político frente a la conducta infractora resulte adecuada y apropiada para ese fin; $c$ ) juridicidad, que consiste en que se realicen acciones permitidas en la ley y que las autoridades electorales puedan actuar en el ámbito de su competencia; d) oportunidad, que refiere a que si la actuación es inmediata al desarollo de los hechos que se consideren ilícitos, y e) razonabilidad, que consiste en que la acción implementada es la que de manera ordinaria se podría exigir a los partidos políticos. ${ }^{9}$

Como se trataba de la responsabilidad indirecta por actos cometidos por los candidatos, el Tribunal Electoral al resolver el recurso de apelación SUP-RAP-157/2010, abordó el tema relativo a la responsa-

9 Dichos criterios dieron motivo a la jurisprudencia 17/2010, con el rubro: RESPONSABILIDAD DE LOS PARTIDOS POLÍticos POR ACTOS DE TERCEROS. CONDICIONES QUE DEBEN CUMPLIR PARA DESLINDARSE. Gaceta de Jurisprudencia y Tesis en materia electoral, Tribunal Electoral del Poder Judicial de la Federación, año 3, núm. 6, 2010, pp. 33 y 34 
bilidad indirecta que se le atribuía a un candidato por haber tolerado la transmisión de un promocional por parte del partido político que lo postuló.

La Sala Superior consideró que los elementos que había tomado en consideración la autoridad administrativa electoral para fincarle responsabilidad administrativa eran insuficientes, toda vez que no era posible inferir válidamente que el candidato hubiera tenido conocimiento pleno de la transmisión del promocional denunciado, porque no existía certeza de que hubiera conocido con toda oportunidad su difusión, para que de esa forma se le responsabilizara por tolerar una conducta infractora; especialmente cuando no se encontraba acreditado que tuvo dicho conocimiento o de que se le hubiera tomado su parecer en la decisión del partido político de transmitirlo en uso de prerrogativas de acceso a radio y televisión.

Por ello, señaló que para presumir de forma fundada que el entonces recurrente estuvo en condiciones de enterarse de la difusión del promocional, era necesario que el mismo se hubiera transmitido en forma periódica y en diferentes horarios, o bien, en los de mayor audiencia, para así contar con un elemento al menos indiciario de que tuvo conocimiento de su transmisión.

De ahí que, la Sala Superior, consideró que si el promocional denunciado se transmitió únicamente un día, entre semana, en cinco canales de televisión y esos diferentes impactos fluctuaron en un tiempo aproximado de veinte minutos, difícilmente podría arribarse a la certera conclusión de que el ciudadano denunciado tuvo conocimiento al haber visualizado el spot que se calificó de irregular.

De esta manera, era necesario que se demostrara que el candidato tuvo conocimiento de su transmisión a efecto de acreditar la responsabilidad indirecta que le fue fincada, por lo que, si dicho extremo (conocimiento de la transmisión del promocional), no quedó colmado, era indebido atribuirle la referida responsabilidad indirecta.

En dicha sentencia, también se estableció que para fincar responsabilidad indirecta al candidato por la difusión por el partido político de los referidos spots, debían tomarse en cuenta los siguientes aspectos: 1) acreditarse fehacientemente el conocimiento del actor del hecho infractor; 2) era desproporcionado exigir al actor deslindarse de actos violatorios de la normatividad electoral, respecto de los cuales no había certeza de que conoció con toda oportunidad su difusión; 3) la inexistencia de un elemento al menos indiciario del conocimiento del 
actor de la irregularidad, y 4) la ausencia de dato, mediante el cual, se acreditara que el actor tuvo conocimiento de la irregularidad o que se le hubiera tomado su parecer. ${ }^{10}$

\section{Aspectos relacionados con la teoría del levantamiento del velo, el abuso del derecho y el fraude a la ley}

Las personas jurídicas al igual que las personas físicas, despliegan conductas y llevan a cabo actos que si bien no se encuentran regulados expresamente por la ley, y que por ello podrían considerarse dentro del marco regulatorio permitido, lo cierto es que, con motivo de sus actividades, pueden presentarse simulaciones que pudieran implicar la transgresión de las finalidades que la norma prevé con su regulación.

En cuanto a este aspecto, la doctrina del levantamiento del velo de la persona jurídica, es un referente para dilucidar las posibles simulaciones o fraudes a la ley que pudieran derivar de una actuación aparentemente lícita pero que puede resultar contraventora a las finalidades perseguidas por la norma. En este sentido, entre las finalidades de esta doctrina se encuentra la de entrar al sustrato mismo de la persona jurídica a efecto de establecer estos extremos.

$\mathrm{Al}$ respecto, cabe hacer mención que en el derecho anglosajón, la idea de fraude resulta más amplia que en nuestro derecho y en ella se subsumen nuestros conceptos de actos fraudulentos de dolo y simulación; los casos son variados, pero en su mayoría se refieren a establecer si existe unidad entre las personas jurídicas y sus miembros o el tratamiento debe realizarse en forma separada; en cuanto a esta postura el tratamiento que se realiza en el derecho anglosajón es que la persona jurídica y sus miembros no pueden ser concebidas en forma separada, ya que tal separación sería tanto como proteger el fraude. Como resultado se levanta el velo de forma que el acto llevado a cabo por la sociedad se repute realizado tanto por ésta como por el socio, por lo que las

10 El referido fallo dio motivo a la tesis VI/2011 con el rubro: RESPONSABILIDAD INDI-

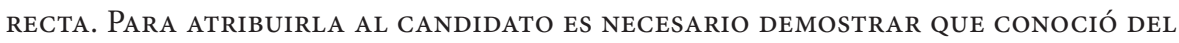
ACTO INFRACTOR. La Sala Superior en sesión pública celebrada el 12 de enero de 2011, aprobó por unanimidad de seis votos la tesis que antecede. Pendiente de publicación. 
relaciones contractuales, obligacionales o los efectos de una sentencia le son extensibles. ${ }^{11}$

En el derecho español, en la que se alude a la posibilidad de investigar el fondo real de la persona jurídica sin detenerse en su forma es la del 8 de enero de 1980, derivada de un recurso de reclamación por responsabilidad civil extracontractual; aunque no alude expresamente la doctrina del levantamiento del velo corporativo, constituye el precedente doctrinal del que arranca la luego más perfeccionada construcción jurisprudencial. ${ }^{12}$

La doctrina del levantamiento del velo ha sido empleada por el Tribunal Supremo español, entre otros: cuando se trate de la utilización de una persona jurídica para eludir el cumplimiento de una norma imperativa, para eludir el cumplimiento de las obligaciones que surjan de un contrato, o bien, para eludir el cumplimiento de obligaciones que surgen de los actos u omisiones en que intervenga cualquier género de culpa o negligencia.

Conforme a lo anterior, la teoría del levantamiento del velo en temas como los expuestos y, en especial, en lo relativo a las formas de participación de los partidos políticos en los procesos electorales como la coalición y la candidatura común, bien pueden aplicarse en temas como financiamiento o rebase de topes de gastos de campaña, con la finalidad de descubrir-encontrar si a través de alguna de ellas se pretende eludir el cumplimiento de la norma u obtener una ventaja indebida que a la postre podría traducirse en inequidad en la contienda.

Hasta aquí hemos realizado una breve referencia a la teoría del levantamiento del velo de las personas jurídicas y, en especial, su aplicación para algunas de las actividades de los partidos políticos; aspecto que también puede relacionarse con actividades como el abuso del derecho y el fraude a la ley que son figuras a las que Manuel Atienza y Ruiz Manero han denominado ilícitos atípicos. ${ }^{13}$

Con el nombre de abuso de un derecho se identifican aquellas acciones que, constituyen casos de ejercicio de un derecho subjetivo y que son, por tanto, acciones, prima facie, permitidas. Sin embargo, adquieren el calificativo de "abusivas" siempre que se den de manera conjunta una serie de circunstancias: $a$ ) la acción debe ser, de entra-

11 Boldó Roda, Carmen, Levantamiento del velo y persona jurídica en el derecho privado español, 4a. ed., España, 2006, pp. 92-94.

12 Ibidem, pp. 185 y 186.

13 Véase Atienza, Manuel y Ruiz Manero, Juan, Ilícitos atípicos, Madrid, Trotta, 2000. 
da, el ejercicio de un derecho subjetivo; $b$ ) que produzca un daño a un interés no protegido por una específica prerrogativa jurídica; $c$ ) la antisocialidad de ese daño, manifestada de forma subjetiva (cuando el derecho se actúa con la intención de perjudicar o sencillamente sin un fin serio y legítimo) u objetiva (cuando el daño proviene de exceso o anormalidad en el ejercicio del derecho).

Otro tema que guarda estrecha vinculación con simulaciones, omisiones o la elusión de la norma, es el fraude a la ley, según el cual, se entiende como una oposición a los principios que constituyen un sistema jurídico, a través de la simulación de actos que aparentemente se ajustan a los presupuestos legales que los regulan. Ello hace necesario que quien ejerce la función jurisdiccional dentro de un Estado constitucional de derecho requiere, entre otras capacidades, la de detectar y reaccionar frente a la forma peculiar de atentado contra el derecho que suponen los ilícitos atípicos: el abuso del derecho, el fraude de ley y la desviación de poder.

Lo anterior es trascendente, porque la simulación de actos legales que traen como resultado un efecto distinto al que se pretende legalmente, o peor aún, que contraviene el objetivo legal, no sólo es lesivo de los sujetos a los que va destinado el resultado de ese acto, sino que vulneran los principios sobre los que se rige el sistema jurídico de que se trate.

La teoría del levantamiento del velo de las personas jurídicas, el abuso del derecho y el fraude a la ley, bien pueden resultar aplicables para casos en los que los partidos políticos pretenden actuar fuera de los cánones y finalidades de la norma, cuya elusión, mediante actos simulados u omisivos, por citar sólo algunos ejemplos, pudiera traducirse en un beneficio indebido en el proceso electoral, aspectos en los cuales es importante que las autoridades electorales, tanto en los ámbitos administrativo y jurisdiccional actúen oportunamente adoptando las medidas necesarias que permitan identificar la irregularidad $\mathrm{y}$, de ser el caso, adoptar las medidas eficaces para inhibirlas.

\section{Las candidaturas comunes}

Existen diversas formas de participación de los partidos en los procesos electorales, de entre las que se encuentran las coaliciones o las can- 
didaturas comunes donde los partidos políticos convienen en postular en conjunto a candidatos a cargos de elección popular, esta últimas, son quizá uno de los temas que poco han sido estudiados, principalmente en cuanto a temas de fiscalización o rebase de topes de gastos de campaña y el deber de cuidado que pudiera derivarse de la actuación irregular de alguno de ellos, lo que podría traducirse en responsabilidad indirecta o culpa in vigilando.

En México, las legislaciones de Baja California Sur, ${ }^{14}$ Coahuila de Zaragoza, ${ }^{15}$ Colima, ${ }^{16}$ Chiapas, Chihuahua, ${ }^{17}$ Distrito Federal, ${ }^{18}$ Michoacán, ${ }^{19}$ Morelos, ${ }^{20}$ San Luis Potosí, ${ }^{21}$ Sonora, ${ }^{22}$ Yucatán, ${ }^{23}$ y Zacatecas, ${ }^{24}$ regulan las candidaturas comunes como una opción más de participación de los partidos políticos en las contiendas electorales locales.

Respecto al Estado de México, el artículo 76 del Código Electoral del Estado de México, establecía a las candidaturas comunes como una forma de participación de los partidos políticos en los comicios de la entidad; sin embargo, los días 21 y 25 de septiembre de 2010, se publicaron en la Gaceta de Gobierno del Estado de México los decretos por los que se reforman diversas disposiciones de la Constitución Política del Estado de México, así como del ordenamiento comicial de la entidad, entre los que se encuentra la supresión de las candidaturas comunes. ${ }^{25}$

14 Ley Electoral del Estado de Baja California Sur, artículos 78-81.

15 Código Electoral del Estado de Coahuila de Zaragoza, artículo 63.

16 Código Electoral del Estado de Colima, artículos 63 Bis 1, a 63, Bis-5.

17 Ley Electoral del Estado de Chihuahua, artículos 73-76

18 Código de Instituciones y Procedimientos Electorales del Distrito Federal, artículo 244.

19 Código Electoral del Estado de Michoacán, artículos 52-61.

${ }^{20}$ Código Electoral del Estado Libre y Soberano de Morelos, artículos 89 y 90.

${ }^{21}$ Ley Electoral del Estado de San Luis Potosí, artículo 46.

22 Código Electoral para el Estado de Sonora, artículos 189-191.

23 Constitución Política del Estado Yucatán, artículo 16, apartado B. Las candidaturas comunes se encuentran reguladas a nivel constitucional local, pero la misma no aparece regulada en la legislación electoral de la entidad.

${ }^{24}$ Ley Electoral del Estado de Zacatecas.

25 Transitorios: ...

Segundo. El presente Decreto entrará en Gobierno del Estado de México.

Tercero. Se derogan las disposiciones de igual o menor jerarquía que se opongan al presente Decreto. 
En cuanto a este aspecto, es importante mencionar que la Suprema Corte de Justicia de la Nación al resolver las acciones de inconstitucionalidad identificadas con las claves $60 / 2009$ y su acumulada $61 / 2009$, así como 26/2010 y acumuladas 27/2010,28/2010 y 29/2010 relativas a la supresión de las candidaturas comunes por parte de las legislaturas de Guanajuato y del Estado de México, respectivamente, se pronunció en el sentido de que dicha supresión se trataba de una modalización del derecho de asociación en materia política que compete regular al legislador local y de ningún modo trasgredía la Constitución federal.

\section{El caso "Estado de México"}

Hasta lo aquí expuesto, podemos decir que los partidos políticos pueden incurrir en responsabilidad por culpa in vigilando por conductas de sus militantes, simpatizantes, por otros partidos políticos que tengan un vínculo jurídico (coaliciones), o cualquier tercero relacionado con sus actividades, pero el tema de la participación de los partidos políticos bajo la figura de candidaturas comunes tratándose de la determinación del financiamiento respecto a los topes de gastos de campaña no se había planteado en el Tribunal Electoral.

Un caso como al que se ha hecho mención, fue sometido a análisis por la Sala Regional Toluca en el juicio de revisión constitucional electoral con la clave ST-JRC-16/2010, en el que el PRI se inconformó con la resolución del Tribunal Electoral del Estado de México en la que se confirmó la sanción que el Consejo General del Instituto Electoral de dicha entidad federativa le había impuesto por culpa in vigilando en el que algunos de los partidos políticos que participaron en candidatura común rebasaron los topes de gastos de campaña.

El problema entonces, surge, medularmente en si es posible sancionar a un partido político que participó en candidatura común, por culpa in vigilando, al no haber tomado medidas para evitar que los partidos que conforman dicha candidatura, rebasen los topes de gastos de campaña o bien, haberse deslindado de manera oportuna mediante un medio eficaz, idóneo y proporcional respecto de las irregularidades cometidas por los demás partidos políticos que la conforman.

En efecto, el asunto se presenta como un verdadero caso frontera o de penumbra de derecho, en el que había que establecer, entre otros aspectos, si el espectro de alcance de la culpa in vigilando, conforme a 
los criterios de la Sala Superior, resultaba también aplicable tratándose de candidaturas comunes.

En la sesión pública de resolución de la Sala Regional Toluca, el proyecto del magistrado Santiago Nieto Castillo, en el que se planteaba confirmar la resolución que confirmaba la sanción por culpa in vigilando del cual se hará referencia más adelante, fue rechazado por la mayoría de los integrantes de dicho órgano jurisdiccional y en el engrose del mismo se revocó dicha sanción.

La postura de la mayoría de los magistrados de la Sala Toluca fue reconocer el caso como frontera, resolviendo en esencia que: 1) el partido sancionado no tenía una posición de garante, es decir, no contaba con un deber específico porque de la legislación aplicable no se desprende obligación alguna; 2) conforme al acuerdo estatutario suscrito por los partidos políticos integrantes de la candidatura común no se instrumentó un mecanismo que permitiera conocer los gastos de cada uno de ellos; 3) no existía dispositivo legal o contractual que obligara al partido sancionado a vigilar a los demás partidos políticos sobre el rebase de topes de gastos de campaña en los que incurrieron; 4) que el sancionado no estuvo en aptitud de conocer las irregularidades sobre el rebase de topes de gastos de campaña en la que incurrieron los demás partidos políticos integrantes de la candidatura común; 5) se consideró una carga excesiva para el partido sancionado el deber de vigilar a los demás partidos políticos integrantes de la referida candidatura; 6) las conductas de los partidos políticos que rebasaron topes de gastos de campaña, se realizaron en un ámbito en el que el partido sancionado por culpa in vigilando no tenía ninguna injerencia.

De esta manera, la Sala Regional Toluca sentó un precedente importante en cuanto al alcance de la culpa in vigilando tratándose de rebase de topes de gastos de campaña de partidos que participen postulando candidaturas comunes, en el sentido de que únicamente procede fincar responsabilidad directa para los partidos políticos que hubieran rebasado los topes de gastos de campaña, sin que exista la posibilidad de sancionar por responsabilidad indirecta a los demás partidos políticos que integran la candidatura común.

\section{El voto particular}

Al respecto, el magistrado Santiago Nieto Castillo, cuyo proyecto inicial fue rechazado por la mayoría de los integrantes de la Sala Toluca, 
planteó un voto particular al disentir sobre las consideraciones que sustentaban el proyecto, puesto que, en su concepto, debió confirmarse la sanción por culpa in vigilando.

Las razones de la disidencia, fueron las que sustentaban el proyecto inicial, mismas que, toralmente se sustentaban en lo siguiente:

a) La responsabilidad deriva de la ley que establece el deber de corresponsabilidad del partido político sancionado en el desarrollo y vigilancia del proceso electoral, de velar por el cumplimiento de los principios del Estado democrático, así como a la violación del principio constitucional de equidad en la contienda, al haber postulado candidaturas en común de las cuales se benefició.

b) Del acuerdo estatutario marco se derivaba un "nexo" contractual del deber de vigilar que las partes en la convención no incurran en actos ilícitos (rebase de topes de gastos de campaña).

c) El hecho de que no se hubiera implementado un mecanismo de vigilancia del financiamiento no eximía al partido político sancionado de la responsabilidad que por culpa in vigilando le correspondía conforme al principio nullum auditur turpitudinem propiam allegans (nadie escucha al que alega en su beneficio su propia torpeza).

d) En el cumplimiento del contrato (acuerdo estatutario marco de la candidatura común), cada uno de los contratantes se encuentra obligado a vigilar que el otro, con motivo de su ejecución o cumplimiento, no cometa ilícitos o vulnere el orden público, los principios generales del derecho y los constitucionales en conformidad con lo resuelto por la Sala Superior en el expediente SUP-RAP-201/2009, del PVEM, del cual se ha hecho referencia.

e) De autos se advertía que el partido sancionado por culpa in vigilando conoció en diversos momentos sobre el rebase de topes de gastos de campaña en el que habían incurrido los demás partidos políticos.

f) El partido político sancionado sí tenía injerencia respecto de las conductas desplegadas por los demás partidos políticos que conformaban la candidatura común en tanto que se benefició de los resultados obtenidos en el proceso electoral.

g) La sanción por responsabilidad indirecta impuesta al Partido Revolucionario Institucional, era acorde a la construcción del criterio de culpa in vigilando que se había venido realizando a par- 
tir de los criterios sustentados por la Sala Superior del Tribunal Electoral.

\section{Algunas reflexiones}

En casos como los expuestos, en especial el relativo a las candidaturas comunes, se ponen de relieve inconsistencias en cuanto a temas como el rebase de topes de gastos de campaña, puesto que si bien en el Estado de México han dejado de existir las candidaturas comunes, lo cierto es que en otras entidades federativas en las que aún se regula esta forma de participación, es necesario establecer criterios eficaces, fundamentalmente en aspectos como las obligaciones derivadas de esta forma de participación, las responsabilidades, la transparencia y la rendición de cuentas; aspectos que, en definitiva, abonarán a una mejor claridad de los procedimientos de fiscalización y la distribución de responsabilidades puesto que al contar con disposiciones claras que regulen estos aspectos será en abono a los principios rectores de la democracia. Uno de ellos es la equidad en la contienda electoral.

\section{Bibliografía}

Atienza, Manuel y Ruiz Manero, Juan, Ilícitos atípicos, Madrid, Trotta, 2000.

Boldó RodA, Carmen, Levantamiento del velo y persona jurídica en el derecho privado español, 4a. ed., España, 2006.

Córdova Vianello, Lorenzo y Murayama, Ciro, Elecciones, dinero y corrupción. Pemexgate y Amigos de Fox, México, Cal y Arena, 2006. Nieto García, Alejandro, Derecho administrativo sancionador, 4a. ed., Madrid, Tecnos, 2005.

\section{Sentencias}

Acción de inconstitucionalidad 60/2009 y su acumulada 61/2009.

Acción de inconstitucionalidad 26/2010 y acumuladas 27/2010, 28/2010 y 29/2010. SUP-RAP-98/2003 y acumulados. 
SUP-RAP-018/2003.

SUP-RAP-186/2008.

SUP-RAP-201/2009.

SUP-RAP-201/2009.

SUP-RAP/198/2011.

SUP-RAP-220/2011.

SUP-RAP-157/2010.

ST-JRC-16/2010.

\section{Legislación}

Código Electoral del Estado de Coahuila de Zaragoza.

Código Electoral del Estado de Colima.

Código de Instituciones y Procedimientos Electorales del Distrito Federal.

Código Electoral del Estado de Michoacán.

Código Electoral del Estado Libre y Soberano de Morelos.

Código Electoral para el Estado de Sonora.

Constitución Política del Estado Yucatán.

Ley Electoral del Estado de Baja California Sur.

Ley Electoral del Estado de Chihuahua.

Ley Electoral del Estado de San Luis Potosí.

Ley Electoral del Estado de Zacatecas. 